Research Article

\title{
Determinants of Overweight or Obesity among Men Aged 20-59 Years: A Case-Control Study Based on the 2016 Ethiopian Demographic and Health Survey
}

\author{
Yohannes Tekalegn (iD \\ Madda Walabu University, Goba Referral Hospital, School of Health Science, Department of Public Health, Goba, Ethiopia \\ Correspondence should be addressed to Yohannes Tekalegn; yohannesefa@gmail.com
}

Received 6 October 2020; Revised 28 March 2021; Accepted 19 April 2021; Published 24 April 2021

Academic Editor: Aron Weller

Copyright ( $) 2021$ Yohannes Tekalegn. This is an open access article distributed under the Creative Commons Attribution License, which permits unrestricted use, distribution, and reproduction in any medium, provided the original work is properly cited.

\begin{abstract}
Background. Evidence shows that overweight or obesity has become a major public health problem in both developed and developing countries. However, there are limited studies conducted to identify the risk factors of overweight or obesity in Ethiopia. Therefore, this study aimed to assess the determinants of overweight or obesity among men aged 20-59 years in Ethiopia. Methods. This study used the 2016 Ethiopian Demographic and Health Survey (EDHS) data. A case-control study was conducted based on the EDHS data; cases were men who were overweight or obese, depending on their body mass index, and controls were men with normal body mass index. Bivariate and multivariate binary logistic regression was performed to assess the determinants of overweight or obesity among the study participants. Results. A total of 610 cases and 2440 controls were included in this study. Men aged 30-39 years (adjusted odds ratio $(\mathrm{AOR})=2.2,95 \% \mathrm{CI}: 1.6-3.0)$ and $\geq 40$ years (AOR $=3.4,95 \%$ CI: 2.5-4.7) had higher odds of being overweight or obese compared to men aged 20-29 years old. The likelihood of overweight or obesity was significantly higher among married men $(\mathrm{AOR}=1.5,95 \% \mathrm{CI}: 1.1-2.0)$, living in urban areas ( $\mathrm{AOR}=3.1,95 \% \mathrm{CI}: 2.1-4.4)$, those in the rich wealth quintile $(\mathrm{AOR}=1.9,95 \% \mathrm{CI}: 1.2-2.9)$, and those with primary $(\mathrm{AOR}=1.6,95 \% \mathrm{CI}: 1.1-2.3)$, secondary $(\mathrm{AOR}=2.6$, 95\% CI: 1.7-3.9), and higher education ( $\mathrm{AOR}=3.6,95 \% \mathrm{CI}: 2.4-5.6)$. Additionally, men watching television at least once a week had higher odds (AOR = 1.5, 95\% CI: 1.1-2.1) of being overweight or obese. Conclusion. Men in the higher wealth quintile, older age, married, higher educational status, watching television at least once a week, urban dwellers, residents of big cities such as Addis Ababa and Harari, and residents of low land like Afar were more likely to be overweight or obese. Therefore, it is essential to design strategies and programs to reduce or prevent overweight or obesity with a special focus on the identified risk factors.
\end{abstract}

\section{Introduction}

The World Health Organization (WHO) has defined obesity as a condition with excessive fat accumulation in the body, to the extent that health is adversely affected [1]. Overweight or obesity results from a positive energy imbalance expressed by a body mass index (BMI) of $25-29.9$ and $\geq 30 \mathrm{~kg} / \mathrm{m}^{2}$, respectively [2,3]. Also, in 2000, the WHO labeled obesity as the most blatantly visible, but most neglected, public health problem worldwide [4]. Overweight or obesity has become a major public health problem in both developing and developed countries as they are causally related to a wide spectrum of chronic noncommunicable diseases including type 2 diabetes, cardiovascular diseases, and cancer [5]. Both generalized obesity and abdominal obesity are associated with an increased risk of morbidity and mortality [6]. Moreover, several studies reported obesity as the welldocumented major risk factor for many noncommunicable diseases and health conditions including hypertension, high lipid concentrations, type-2 diabetes, coronary heart disease, stroke, and certain cancers [5, 7-11]. According to the WHO report, in 2016, more than 1.9 billion adults aged 18 years and older were overweight or obese [12]. The global burden of overweight or obesity is recorded to be 4 million deaths and 40 million disability-adjusted life years among adults globally in 2015 [13].

The prevalence of overweight or obesity is increasing globally in both developing and developed countries, 
especially, those with rapid cultural and social changes [14-19]. Many low- and middle-income countries are now facing a "double burden" of disease. While these countries continue to deal with the problems of infectious diseases and undernutrition, they are also experiencing a rapid increase in noncommunicable disease risk factors such as obesity and overweight, particularly in urban settings [12].

In Africa, the body mass index (BMI) increased over time across all regions, which parallels the global average. The prevalence of overweight or obesity is estimated to be $20 \%-50 \%$ by 2025 in Africa [20]. In Sub-Saharan Africa countries, overweight/obesity levels are still lower than in high-income countries but certainly higher than they were two decades ago and increasing at alarming rates [21, 22]. Demographic Health Survey (DHS) analysis of 32 SubSaharan African countries revealed that the pooled prevalence of overweight in the region was $15.9 \%$ with the lowest in Madagascar (5.6\%) and the highest in Swaziland (27.7\%); similarly, the prevalence of obesity was also the lowest in Madagascar (1.1\%) and the highest in Swaziland (23.0\%) [23].

In Ethiopia, noncommunicable diseases (NCDs) account for $42 \%$ of deaths. Among these, $27 \%$ are premature deaths occurring before 70 years of age. Disability-adjusted life years (DALYs) due to NCDs in the country have increased from $20 \%$ in 1990 to $69 \%$ in 2015, which is more than double that of communicable maternal, neonatal, and nutritional problems combined $[24,25]$. The analysis of the Ethiopian Demographic Health Survey (EDHS) found that the prevalence of overweight or obesity in urban settings was $12.1 \%$ and $2.8 \%$, respectively [26]. Recently, the prevalence of adult overweight or obesity has increased from $4 \%$ in 2000 to $6 \%$ in 2016 [27]. Similarly, different pocket area studies showed that the prevalence of adult overweight ranges from $16.1 \%$ to $25.3 \%$ and obesity ranges from $5.6 \%$ to $16.2 \%[26,28-30]$. As it is known, overweight or obesity has become a complex problem resulting from a combination of genetic, behavioral, cultural, and environmental influences [31-33].

Although many studies reporting the prevalence and determinants of overweight or obesity, there are limited studies on this aspect that reported determinants of overweight or obesity among men aged $20-59$ years at the national level. Therefore, identifying determinants will have paramount importance in the prevention and control of these emerging public challenges in Ethiopia. The information can be used as baseline evidence for program planners, policymakers, and researchers working on the prevention of chronic noncommunicable diseases. It will also help community members by providing information on the risk factors of overweight or obesity.

\section{Methods and Materials}

2.1. Data Sources. This case-control study was conducted using 2016 Ethiopian Demographic and Health Survey (EDHS), the most recent national survey conducted by the Ethiopian Central Statistical Agency (ECSA). Data collection took place from January 18, 2016, to June 27, 2016 [34].
2.2. Sampling Procedures and Population. The 2016 EDHS data was collected using a sampling frame from the Ethiopian population and housing census which was conducted in 2007 by the Ethiopian Central Statistical Agency. The survey was designed to represent the country as a whole, for urban and rural areas separately. All of the nine administrative regions and the two city administrations in Ethiopia were included in the survey. A two-stage stratified cluster sampling was used. Each region and one city administration were stratified into urban and rural, except Addis Ababa, which is entirely urban. A total of 645 enumeration areas (202 in urban areas and 443 in rural areas) were selected with probability proportional to the size of enumeration areas and with independent selection in each sampling stratum. In the second stage, a fixed number of 28 households per cluster were selected with an equal probability systematic selection from the newly created household listing [34]. To calculate the nutritional status of men, we merged anthropometric variables from household members recode (PR file) to the men's recode (MR file) using the cluster, household, and line numbers [35]. After merging both datasets, there were a total of 610 overweight or obese samples, based on their body mass index (BMI), and all of them were included in the analysis as a case. We used one to four cases to control the ratio; thus, 2440 samples were randomly selected from a total of 7059 men with normal BMI.

\subsection{Data Collection and Anthropometric Measurements.} EDHS survey data was collected using a structured interviewer-administered questionnaire. All men aged 20-59 years who were either permanent residents of selected households or visitors who stayed in the household the night before the survey were eligible to be interviewed for a man's questionnaire. The interview was carried out using tablet computers to record responses. Height and weight of all men aged 20-59 were measured. Weight was measured using lightweight SECA mother-infant scales with a digital screen designed and manufactured under the guidance of UNICEF. Height measurements were carried out using a Shorr measuring board. A detailed explanation of sampling procedures and the data collection process can be found elsewhere [34].

2.4. Outcome Variable. Overweight or obesity is the outcome variable of this study which was derived from the body mass index (BMI) data. BMI was calculated as weight in kilogram divided by the square of height in meters. Men with BMI greater than or equal to $25.0 \mathrm{~kg} / \mathrm{m}^{2}$ were categorized as overweight or obese and characterized as cases. Men with a BMI of $18.5-24.99 \mathrm{~kg} / \mathrm{m}^{2}$ were categorized as normal-weight men and considered as controls for this study [6].

2.5. Independent Variables. This study included demographic, economic, and geographic variables to assess determinants of overweight or obesity among men aged 20-59 years. Depending on the availability of the data, biological plausibility, and evidence from previously published 
literature, the following variables were included as explanatory variables: age (which is categorized as $20-29,30-39$, and $\geq 40$ years old), marital status (recoded as single, married, and separated/divorced/widowed), educational status (recoded as no education, primary, secondary, and higher education), current employment status (working and not working), frequency of watching television (not at all, less than once a week, and at least once a week), frequency of listening to the radio (not at all, less than once a week, and at least once a week), frequency of reading newspaper or magazine (not at all, less than once a week, and at least once a week), wealth index (recoded as poor, middle, and rich), place of residence (urban or rural), and administrative regions (Tigray, Afar, Amhara, Oromia, Somali, Benishangul, SNNPR, Gambela, Harari, Diredawa, and Addis Ababa).

2.6. Data Analysis Procedures. Data was analyzed using STATA version 14 software. Variables with $P$ value $<0.05$ in bivariate binary logistic regression were included in the multivariate binary logistic regression analysis. Adjusted odds ratio (AOR) with 95\% confidence interval (CI) was used to report the association between dependent and independent variables. Statistical significance of the final model was set at $P$ value $<0.05$. The fitness of the model was tested using Hosmer and Lemeshow goodness of fit statistics $(P=0.71)$. Multicollinearity between independent variables was checked using variance inflation factor (VIF). The mean value of VIF was 1.95, which is less than the cutoff point [36].

2.7. Ethical Considerations. This study used secondary data from the Ethiopian Demographic and Health Survey which was conducted upon the approval of the Ethiopian National Research Ethics Review Committee. The permission to access the datasets was obtained from the MEASURE DHS project website.

\section{Results}

3.1. Characteristics of Study Participants. A total of 610 overweight/obese men and 2440 men with normal body mass index were included in this analysis. The age of the study participants ranges from 20 to 59 years old. Five hundred forty-four cases (82.9\%) and 702 (28.8\%) of controls were urban dwellers. With regard to wealth index, 561 (91.9\%) of cases and 1235 (50.6\%) of controls were rich. Four hundred forty-four $(72.8 \%)$ of cases and $1736(71.1 \%)$ of controls were married. In terms of religion, $380(62.3 \%)$ of cases and 1115 (45.7\%) of controls were Orthodox (Table 1).

3.2. Determinants of Overweight or Obesity. In the final multivariate binary logistic regression analysis, age, marital status, educational level, frequency of watching television, wealth index, place of residence, and region of residence were significantly associated with being overweight or obese. The odds of being overweight or obese were 2.2 times $(\mathrm{AOR}=2.2,95 \% \mathrm{CI}: 1.6-3.0)$ and 3.4 times $(\mathrm{AOR}=3.4,95 \%$ CI: 2.5-4.7) higher among men aged $30-39$ years and $\geq 40$ years, respectively, compared to men aged 20-29 years. Married men had 1.5 times (AOR $=1.5,95 \%$ CI: $1.1-2.0$ ) higher odds of being overweight or obese compared to singles. Men with primary, secondary, and higher education had 1.6 times $(\mathrm{AOR}=1.6,95 \% \mathrm{CI}: 1.1-2.3), 2.6$ times $(\mathrm{AOR}=2.6,95 \% \mathrm{CI}: 1.7-3.9)$, and $3.6(\mathrm{AOR}=3.6,95 \% \mathrm{CI}$ : 2.4-5.6) higher odds of being overweight or obese, respectively, compared to men with no education. Men watching television at least once a week had 1.5 times (AOR $=1.5,95 \%$ CI: 1.1-2.1) higher odds of overweight or obesity compared to men not watching television at all. Men living in urban areas were 3.1 times $(\mathrm{AOR}=3.1,95 \% \mathrm{CI}$ : 2.1-4.4) more likely to be overweight or obese compared to rural. The likelihood of being overweight or obese was higher among men in rich quintiles ( $\mathrm{AOR}=1.9,95 \% \mathrm{CI}$ : 1.2-2.9) compared to men in the poor quintiles. In terms of regional distribution, men living in Addis Ababa ( $\mathrm{AOR}=1.7,95 \% \mathrm{CI}$ : 1.1-2.7), Harari $(\mathrm{AOR}=1.8,95 \% \mathrm{CI}: 1.1-3.2)$, and Afar $(\mathrm{AOR}=2.0,95 \% \mathrm{CI}: 1.1-3.9)$ were more likely to be overweight or obese compared to men living in Tigray region (Table 2).

\section{Discussion}

This study used a case-control study to assess determinants of overweight or obesity among men aged 20-59 years in Ethiopia. The study used the 2016 Ethiopian Demographic and Health Survey data, which was a nationally representative survey with an adequate sample size. In this study, age, marital status, educational status, frequency of television watching, wealth index, place of residence, and region of residence were found to be determinants of overweight or obesity.

The likelihood of overweight or obese was 3.1 times higher among urban dwellers compared to rural dwellers. This finding is consistent with studies conducted in Ethiopia [37-39] and elsewhere [38, 40, 41]. This could be related to the fact that urban residents are more likely to follow the Western diet, more likely to use public transportations to go to work daily, and less likely to engage in physically demanding work which might expose them to overweight or obesity [42]. On the contrary, men living in rural areas are more likely to engage in physically demanding work such as agricultural activities and less likely to gain excessive weight.

The odds of being overweight or obese were higher among residents of Addis Ababa and Harari compared to residents of the Tigray region. This might be related to the fact that Addis Ababa and Harari are entirely urban and residents of these areas might be exposed to overweight or obesity as a consequence of lifestyle related to urbanization. This finding is similar to previous studies conducted in Ethiopia [26, 43]. Similarly, residents of the Afar region were more likely to be overweight or obese. These areas were drought-prone areas and more likely to consume food items supplied by humanitarian aid [44] which might expose them to overweight or obesity [45]. This finding is supported by previous studies in Ethiopia [38, 43].

Men from the rich wealth quintile were 1.9 times more likely to be overweight or obese compared to their 
TABLE 1: Sociodemographic characteristics of men aged 20-59, EDHS, 2016.

\begin{tabular}{|c|c|c|}
\hline Variables & Cases, $n(\%) N=610$ & Control, $n(\%) N=2440$ \\
\hline \multicolumn{3}{|l|}{ Age category } \\
\hline $20-29$ & $131(21.5)$ & $935(38.3)$ \\
\hline $30-39$ & $212(34.7)$ & $735(30.1)$ \\
\hline$\geq 40$ & $267(43.8)$ & $770(31.6)$ \\
\hline \multicolumn{3}{|l|}{ Marital status } \\
\hline Single & $139(22.8)$ & $613(25.1)$ \\
\hline Married & $444(72.8)$ & $1736(71.1)$ \\
\hline Separated/divorced/widowed & $27(4.4)$ & $91(3.8)$ \\
\hline \multicolumn{3}{|l|}{ Religion } \\
\hline Orthodox & $380(62.3)$ & $1115(45.7)$ \\
\hline Muslim & $157(25.7)$ & $859(35.2)$ \\
\hline Protestant & $63(10.3)$ & $424(17.4)$ \\
\hline Others $^{\mathrm{a}}$ & $10(1.6)$ & $42(1.7)$ \\
\hline \multicolumn{3}{|l|}{ Educational level } \\
\hline No education & $50(8.2)$ & $792(32.5)$ \\
\hline Primary & $134(22.0)$ & $951(39.0)$ \\
\hline Secondary & $165(27.0)$ & $371(15.2)$ \\
\hline Higher & $261(42.8)$ & $326(13.3)$ \\
\hline \multicolumn{3}{|l|}{ Currently working } \\
\hline No & $35(5.7)$ & $198(8.1)$ \\
\hline Yes & $575(94.3)$ & $2242(91.9)$ \\
\hline \multicolumn{3}{|c|}{ Frequency of watching television } \\
\hline Not at all & $82(13.5)$ & $1171(48.0)$ \\
\hline Less than once a week & $95(15.6)$ & $629(25.8)$ \\
\hline At least once a week & $433(70.9)$ & $640(26.2)$ \\
\hline \multicolumn{3}{|l|}{ Frequency of listening radio } \\
\hline Not at all & $142(23.3)$ & $1079(44.2)$ \\
\hline Less than once a week & $135(22.1)$ & $612(25.1)$ \\
\hline At least once a week & $333(54.6)$ & $749(30.7)$ \\
\hline \multicolumn{3}{|c|}{ Frequency of reading newspaper or magazine } \\
\hline Not at all & $236(38.7)$ & $1676(68.7)$ \\
\hline Less than once a week & $193(31.6)$ & $520(21.3)$ \\
\hline At least once a week & $181(29.7)$ & $244(10.0)$ \\
\hline \multicolumn{3}{|l|}{ Wealth index } \\
\hline Poor & $38(6.3)$ & $840(34.4)$ \\
\hline Middle & $11(1.8)$ & $365(15.0)$ \\
\hline Rich & $561(91.9)$ & $1235(50.6)$ \\
\hline \multicolumn{3}{|l|}{ Place of residence } \\
\hline Urban & $506(82.9)$ & $702(28.8)$ \\
\hline Rural & $104(17.1)$ & $1738(71.2)$ \\
\hline \multicolumn{3}{|l|}{ Region } \\
\hline Tigray & $37(6.1)$ & $237(9.7)$ \\
\hline Afar & $23(3.8)$ & $102(4.2)$ \\
\hline Amhara & $23(3.7)$ & $363(14.9)$ \\
\hline Oromia & $39(6.4)$ & $348(14.3)$ \\
\hline Somali & $29(4.8)$ & $143(5.8)$ \\
\hline Benishangul & $24(3.9)$ & $181(7.4)$ \\
\hline $\mathrm{SNNPR}^{\mathrm{b}}$ & $39(6.4)$ & $372(15.2)$ \\
\hline Gambela & $31(5.1)$ & $160(6.6)$ \\
\hline Harari & $51(8.4)$ & $116(4.7)$ \\
\hline Addis Ababa & $232(38.0)$ & $252(10.3)$ \\
\hline Dire dawa & $82(13.4)$ & $166(6.8)$ \\
\hline
\end{tabular}

${ }^{\mathrm{a}}$ Catholic, traditional, and others. ${ }^{\mathrm{b}}$ South Nation, Nationalities, and People's Region.

counterparts. This study also revealed that men with secondary and higher education were more likely to be overweight or obese compared to men with no education. The wealth quintile may be a proxy indicator for characteristics such as access to quality health care, being higher income, dietary diversification, and consumption of energy-dense food. Additionally, educated and rich men are less likely to engage in physically demanding work and more likely to follow a sedentary lifestyle. This finding is supported by multiple studies in Ethiopia and elsewhere [26, 30, 39, 41, 46, 47]. However, some studies reported a negative association between educational status and 
TABLE 2: Determinants of overweight or obesity among men aged 20-59, further analysis of EDHS, 2016.

\begin{tabular}{|c|c|c|}
\hline Variables & COR $(95 \% \mathrm{CI})$ & $\operatorname{AOR}^{a}(95 \% C I)$ \\
\hline \multicolumn{3}{|l|}{ Age category } \\
\hline $20-29$ & 1 & 1 \\
\hline $30-39$ & $2.1(1.6-2.6)$ & $2.2(1.6-3.0)^{* *}$ \\
\hline$\geq 40$ & $2.5(1.9-3.1)$ & $3.4(2.5-4.7)^{* *}$ \\
\hline \multicolumn{3}{|l|}{ Marital status } \\
\hline Single & 1 & 1 \\
\hline Married & $1.1(0.9-1.4)$ & $1.5(1.1-2.0)^{* *}$ \\
\hline Separated/divorced/widowed & $1.3(0.8-2.1)$ & $1.0(0.6-1.8)$ \\
\hline \multicolumn{3}{|l|}{ Educational level } \\
\hline No education & 1 & 1 \\
\hline Primary & $2.2(1.6-3.1)$ & $1.6(1.1-2.3)^{* *}$ \\
\hline Secondary & $7.0(5.0-9.9)$ & $2.6(1.7-3.9)^{* *}$ \\
\hline Higher & $12.7(9.1-17.6)$ & $3.6(2.4-5.6)^{* *}$ \\
\hline \multicolumn{3}{|l|}{ Currently working } \\
\hline No & $0.7(0.5-0.9)$ & $0.6(0.4-1.0)$ \\
\hline Yes & 1 & 1 \\
\hline \multicolumn{3}{|c|}{ Frequency of watching television } \\
\hline Not at all & 1 & 1 \\
\hline Less than once a week & $2.1(1.6-2.9)$ & $0.8(0.5-1.2)$ \\
\hline At least once a week & $9.6(7.5-12.5)$ & $1.5(1.1-2.1)^{* *}$ \\
\hline \multicolumn{3}{|c|}{ Frequency of listening to the radio } \\
\hline Not at all & 1 & 1 \\
\hline Less than once a week & $1.7(1.3-2.2)$ & $1.2(0.8-1.7)$ \\
\hline At least once a week & $3.4(2.7-4.2)$ & $1.1(0.9-1.6)$ \\
\hline \multicolumn{3}{|c|}{ Frequency of reading newspaper or magazine } \\
\hline Not at all & 1 & 1 \\
\hline Less than once a week & $2.6(2.1-3.3)$ & $0.9(0.7-1.2)$ \\
\hline At least once a week & $5.3(4.2-6.7)$ & $1.1(0.8-1.4)$ \\
\hline \multicolumn{3}{|l|}{ Wealth index } \\
\hline Poor & 1 & 1 \\
\hline Middle & $0.7(0.3-1.3)$ & $0.6(0.3-1.3)$ \\
\hline Rich & $10.0(7.1-14.1)$ & $1.9(1.2-2.9)^{* *}$ \\
\hline \multicolumn{3}{|l|}{ Place of residence } \\
\hline Urban & $12.0(9.6-15.1)$ & $3.1(2.1-4.4)^{* * *}$ \\
\hline Rural & 1 & 1 \\
\hline \multicolumn{3}{|l|}{ Region } \\
\hline Tigray & 1 & 1 \\
\hline Afar & $1.4(0.8-2.6)$ & $2.0(1.1-3.9)^{* *}$ \\
\hline Amhara & $0.4(0.2-0.7)$ & $0.6(0.3-1.1)$ \\
\hline Oromia & $0.7(0.4-1.1)$ & $1.0(0.6-1.8)$ \\
\hline Somali & $1.3(0.8-2.2)$ & $1.5(0.8-2.8)$ \\
\hline Benishangul & $0.8(0.5-1.5)$ & $1.4(0.7-2.6)$ \\
\hline $\mathrm{SNNPR}^{\mathrm{b}}$ & $0.7(0.4-1.1)$ & $1.0(0.6-1.9)$ \\
\hline Gambela & $1.2(0.7-2.0)$ & $0.9(0.5-1.6)$ \\
\hline Harari & $2.8(1.7-4.5)$ & $1.8(1.1-3.2)^{* *}$ \\
\hline Addis Ababa & $5.9(4.0-8.7)$ & $1.7(1.1-2.7)^{* *}$ \\
\hline Dire dawa & $3.2(2.0-4.9)$ & $1.4(0.9-2.4)$ \\
\hline
\end{tabular}

${ }^{a}$ Adjusted for age, marital status, educational status, television watching, residence, wealth index, and region. ${ }^{\mathrm{b}}$ South nation, nationalities, and people's region. ${ }^{* *}$ Statistically significant in multivariate logistic regression model at $p$ value $<0.05$.

overweight or obesity [48-50]. It is important to further explore the impact of education on the body mass index with a strong study design.

This analysis indicated that older age and married men had higher odds of being overweight or obese. In line with this study, multiple studies supported a positive association between age and risk of being overweight or obese
$[26,30,37,40,41,46]$. As age increases, the level of physical exercise tends to decrease, which increases the risk of being overweight or obese. Likewise, the condition of being overweight or obese was higher among married men compared to unmarried men [40,51-53]. Married men are less likely to worry about their body image which in turn increases the risk of being overweight or obese. It might also be explained by the fact that a big body size is considered a sign of success and good health, which could contribute to married men being overweight or obese.

Men watching television at least once a weak had 1.8 times higher odds of being overweight or obese compared to those not watching television at all. This finding is corroborated by several studies [54-61]. Men who have a habit of television watching are more likely to stay physically inactive and they are more likely to be exposed to the advertisement of alcohol and unhealthy foods which increases the risk of being overweight or obese.

This study tried to assess the determinants of overweight or obesity among men aged 20-59 years of age. Among the strength of the study, this is the first study to assess the determinants of obesity among Ethiopian men using Demographic and Health Survey data which is nationally representative data. Furthermore, anthropometric measurements were measured by trained data collectors and validated instruments. However, the findings of this study should be used in light of the following limitations. First, due to the cross-sectional nature of the data, the cause-effect relationship between outcome and independent variables cannot be established. Secondly, due to the secondary nature of the data, some important variables which can affect the likelihood overweight or obesity such as dietary habit and physical activity were not measured. Lastly, indicators of central obesity like waist and hip circumferences were not measured by this survey.

\section{Conclusion}

The study assessed the determinants of overweight or obesity. Men with characteristics like higher wealth quintile, older age, higher educational status, and urban dwellers were more likely to be overweight or obese. Being married, watching television at least once a week, and being residents of big cities such as Addis Ababa and Harari, and residents of lowland like Afar were also found to be significant determinants of overweight or obesity. Therefore, it is essential to design strategies and programs to reduce or prevent overweight or obesity with a special focus on identified risk factors in this study and other similar findings.

\section{Abbreviations}

AOR: Adjusted odds ratio

CI: Confidence interval

COR: Crude odds ratio

DHS: Demographic and Health Survey

EDHS: Ethiopian Demographic and Health Survey. 


\section{Data Availability}

The data that support the findings of this study are available from the MEASURE DHS project upon reasonable request after submission of the concept paper.

\section{Conflicts of Interest}

The authors declare that they have no conflicts of interest.

\section{Authors' Contributions}

YT performed data analysis, wrote the original draft of the manuscript, approved the final manuscript, and agreed to be accountable for all aspects of the work.

\section{Acknowledgments}

The author is grateful to MEASURE DHS and ICF International for providing the 2016 EDHS data for this analysis.

\section{References}

[1] D. R. Wagner and V. H. Heyward, "Techniques of body composition assessment: a review of laboratory and field methods," Research Quarterly for Exercise and Sport, vol. 70, no. 2, pp. 135-149, 1999.

[2] 2014 Control CfD Prevention. Overweight or obesity: adult obesity facts.

[3] E. S. Kasu, A. Ayim, and J. Tampouri, "Assessment health care services among health care workers in holy Karbala governorate," Journal of Biology, Agriculture and Healthcare, vol. 5, 2015.

[4] World Health Organization, Obesity: Preventing and Managing the Global Epidemic, World Health Organization, Geneva, Switzerland, 2000.

[5] J. S. Tabrizi, H. Sadeghi-Bazargani, M. Farahbakhsh, L. Nikniaz, and Z. Nikniaz, "Prevalence and associated factors of prehypertension and hypertension in Iranian population: the lifestyle promotion project (LPP)," PLoS One, vol. 11, no. 10, Article ID e0165264, 2016.

[6] World Health Organization, Waist circumference and waisthip ratio: report of a WHO expert consultation, World Health Organization, Geneva, Switzerland, 2008.

[7] H. B. Hubert, M. Feinleib, P. M. McNamara, and W. P. Castelli, "Obesity as an independent risk factor for cardiovascular disease: a 26-year follow-up of participants in the Framingham Heart Study," Circulation, vol. 67, no. 5, pp. 968-977, 1983.

[8] E. E. Calle, C. Rodriguez, K. Walker-Thurmond, and M. J. Thun, "Overweight, obesity, and mortality from cancer in a prospectively studied cohort of U.S. Adults," New England Journal of Medicine, vol. 348, no. 17, pp. 1625-1638, 2003.

[9] A. Molarius and J. Seidell, "Selection of anthropometric indicators for classification of abdominal fatness- a critical review," International Journal of Obesity, vol. 22, no. 8, pp. 719-727, 1998.

[10] C. Kragelund and T. Omland, "A farewell to body-mass index?” The Lancet, vol. 366, no. 9497, pp. 1589-1591, 2005.

[11] J. R. Sowers, "Obesity as a cardiovascular risk factor," The American Journal of Medicine, vol. 115, no. 8, pp. 37-41, 2003.

[12] World Health Organization, 2008, http://www.who.int/newsroom/fact-sheets/detail/obesity-and-overweight.
[13] G. B. D. O. Collaborators, A. Afshin, M. H. Forouzanfar et al., "Health effects of overweight or obesity in 195 countries over 25 years," The New England Journal of Medicine, vol. 377, no. 1, pp. 13-27, 2017.

[14] World Health Organization, Obesity and Overweight [Fact Sheet No 311], 2012, World Health Organization, Geneva, Switzerland, 2015.

[15] L. McLaren, "Socioeconomic status and obesity," Epidemiologic Reviews, vol. 29, no. 1, pp. 29-48, 2007.

[16] A. J. Olufemi and L. L. Abiodun, "Prevalence of overweight or obesity in an institutionalized multi ethnic based male adult sample," International Journal of Humanities and Social Science, vol. 3, no. 5, pp. 234-2013, 2013.

[17] J. Sen, N. Mondal, and S. Dutta, "Factors affecting overweight or obesity among urban adults: a cross-sectional study," Epidemiology, Biostatistics and Public Health, vol. 10, no. 1, 2013.

[18] F. Amin, S. S. Fatima, N. Islam, and A. H. Gilani, "Prevalence of obesity and overweight, its clinical markers and associated factors in a high risk South-Asian population," BMC Obesity, vol. 2, no. 1, p. 16, 2015.

[19] W. Zukiewicz-Sobczak, P. Wróblewska, J. Zwolinski et al., "Obesity and poverty paradox in developed countries," $A n$ nals of Agricultural and Environmental Medicine, vol. 21, no. 3, 2014.

[20] C. G. Victora, L. Adair, C. Fall et al., "Maternal and child undernutrition: consequences for adult health and human capital," The Lancet, vol. 371, no. 9609, pp. 340-357, 2008.

[21] A. Cois and C. Day, "Obesity trends and risk factors in the South African adult population," BMC Obesity, vol. 2, no. 1, p. 42, 2015.

[22] N. P. Steyn and Z. J. Mchiza, "Obesity and the nutrition transition in sub-saharan Africa," Annals of the New York Academy of Sciences, vol. 1311, no. 1, pp. 88-101, 2014.

[23] S. Neupane, K. Prakash, and D. T. Doku, "Overweight or obesity among women: analysis of demographic and health survey data from 32 Sub-Saharan African Countries," BMC Public Health, vol. 16, no. 1, p. 30, 2015.

[24] A. Misganaw, T. N. Haregu, K. Deribe et al., "National mortality burden due to communicable, non-communicable, and other diseases in Ethiopia, 1990-2015: findings from the Global Burden of Disease Study 2015," Population Health Metrics, vol. 15, no. 1, p. 29, 2017.

[25] T. J. Bollyky, T. Templin, M. Cohen, and J. L. Dieleman, "Lower-income countries that face the most rapid shift in noncommunicable disease burden are also the least prepared," Health Affairs, vol. 36, no. 11, pp. 1866-1875, 2017.

[26] S. Abrha, S. Shiferaw, and K. Y. Ahmed, "Overweight or obesity and its socio-demographic correlates among urban Ethiopian women: evidence from the 2011 EDHS," BMC Public Health, vol. 16, no. 1, p. 636, 2016.

[27] C. ICF, Central statistical agency [Ethiopia] and ICF international Ethiopia Demographic and Health Survey, 2011.

[28] B. Moges, B. Amare, B. Fantahun, and A. Kassu, "High prevalence of overweight, obesity, and hypertension with increased risk to cardiovascular disorders among adults in northwest Ethiopia: a cross sectional study," BMC Cardiovascular Disorders, vol. 14, no. 1, p. 155, 2014.

[29] M. Shegaze, M. Wondafrash, A. A. Alemayehu et al., "Magnitude and determinants of overweight or obesity among high school adolescents in Addis Ababa, Ethiopia," International Journal of Medical, Health, Biomedical, Bioengineering and Pharmaceutical Engineering, vol. 10, no. 10, pp. 215-221, 2016. 
[30] Y. Tebekaw, C. Teller, and U. Colón-Ramos, "The burden of underweight and overweight among women in Addis Ababa, Ethiopia," BMC Public Health, vol. 14, no. 1, p. 1126, 2014.

[31] P. Shinde, A. Pawar, and P. P. Shinde, "Prevalence of overweight \& obesity in adult urban women," Journal of Evolution of Medical and Dental Sciences, vol. 2, no. 4, pp. 364-368, 2013.

[32] G. A. Shayo and F. M. Mugusi, "Prevalence of obesity and associated risk factors among adults in Kinondoni municipal district, Dar es Salaam Tanzania," BMC Public Health, vol. 11, no. 1, p. 365, 2011.

[33] N. J. Olsen and B. L. Heitmann, "Intake of calorically sweetened beverages and obesity," Obesity Reviews, vol. 10, no. 1, pp. 68-75, 2009.

[34] C. S. Agency, "Ethiopian demographic and health survey 2016: key indicators report," The DHS Program ICF, vol. 363, p. 364, 2017.

[35] T. N. Croft, M. J. Aileen, C. K. A. Marshall et al., Guide to DHS Statistics, ICF, Rockville, Maryland, USA, 2018.

[36] H. Midi, S. K. Sarkar, and S. Rana, "Collinearity diagnostics of binary logistic regression model," Journal of Interdisciplinary Mathematics, vol. 13, no. 3, pp. 253-267, 2010.

[37] T. Mekonnen, W. Animaw, and Y. Seyum, "Overweight/ obesity among adults in North-Western Ethiopia: a community-based cross sectional study," Arch Public Health, vol. 76, no. 18, pp. 018-0262, 2018.

[38] T. D. Delbiso, J. M. Rodriguez-Llanes, C. Altare, B. Masquelier, and D. Guha-Sapir, "Health at the borders: bayesian multilevel analysis of women's malnutrition determinants in Ethiopia," Global Health Action, vol. 9, no. 1, p. 30204, 2016.

[39] Y. Yeshaw, S. A. Kebede, A. M. Liyew et al., "Determinants of overweight/obesity among reproductive age group women in Ethiopia: multilevel analysis of Ethiopian demographic and health survey," BMJ Open, vol. 10, no. 3, Article ID e034963, 2020.

[40] M. Janghorbani, M. Amini, W. C. Willett et al., "First nationwide survey of prevalence of overweight, underweight, and abdominal obesity in Iranian adults," Obesity, vol. 15, no. 11, pp. 2797-2808, 2007.

[41] D. T. Doku and S. Neupane, "Double burden of malnutrition: increasing overweight or obesity and stall underweight trends among Ghanaian women," BMC Public Health, vol. 15, no. 1, p. 670, 2015.

[42] B. M. Popkin, S. Paeratakul, F. Zhai, and K. Ge, "A review of dietary and environmental correlates of obesity with emphasis on developing countries," Obesity Research, vol. 3, no. S2, pp. 145s-153s, 1995.

[43] W. Mekonnen and A. Bogale, "Determinants of obesity among women of childbearing age in urban areas of Ethiopia," International Journal of Nutrition and Food Science, vol. 6, no. 3, 2017.

[44] T. Hagmann and A. Mulugeta, "Pastoral conflicts and statebuilding in the Ethiopian Lowlands," Africa Spectrum, vol. 43, pp. 19-37, 2008.

[45] C. S. Grijalva-Eternod, J. C. K. Wells, M. Cortina-Borja et al., "The double burden of obesity and malnutrition in a protracted emergency setting: a crosssectional study of Western Sahara refugees," PLOS Medicine, vol. 9, 2012

[46] T. Darebo, A. Mesfin, and S. Gebremedhin, "Prevalence and factors associated with overweight or obesity among adults in Hawassa city, southern Ethiopia: a community based crosssectional study," BMC Obesity, vol. 6, p. 8, 2019.

[47] S. Dagne, Y. Assefa Gelaw, Z. Abebe, and M. Mesele Wassie, "Factors associated with overweight and obesity among adults in northeast Ethiopia: a cross-sectional study," Diabetes,
Metabolic Syndrome and Obesity: Targets and Therapy, vol. 12, pp. 391-399, 2019.

[48] R. Shrimpton and C. Rokx, "The double burden of malnutrition: a Review of Global Evidence," Health, Nutrition and Population (HNP) Discussion Paper, The International Bank for Reconstruction and Development/The World Bank, Washington, DC, 2012.

[49] B. M. Popkin, "Recent dynamics suggest selected countries catching up to US obesity," The American Journal of Clinical Nutrition, vol. 91, pp. 284S-288S, 2010.

[50] R. W. Mayega, F. Makumbi, E. Rutebemberwa et al., "Modifiable socio-behavioural factors associated with overweight and hypertension among persons aged 35 to 60 Years in eastern Uganda," PLoS One, vol. 7, no. 10, Article ID e47632, 2012.

[51] A. Lipowicz, S. Gronkiewicz, and R. M. Malina, "Body mass index, overweight and obesity in married and never married men and women in Poland," American Journal of Human Biology, vol. 14, no. 4, pp. 468-475, 2002.

[52] L. K. Cobb, M. A. McAdams-DeMarco, K. A. Gudzune et al., "Changes in body mass index and obesity risk in married couples over 25 years," American Journal of Epidemiology, vol. 183, no. 5, pp. 435-443, 2016.

[53] J. Sobal, B. S. Rauschenbach, and E. A. Frongillo, "Marital status, fatness and obesity," Social Science \& Medicine, vol. 35, no. 7, pp. 915-923, 1992.

[54] B. Ghose, "Frequency of TV viewing and prevalence of overweight or obesity among adult women in Bangladesh: across-sectional study," BMJ Open, vol. 7, no. 1, Article ID e014399, 2017.

[55] R. Das Gupta, H. SajalI, M. Hasan, I. Sutradhar, M. R. Haider, and M. Sarker, "Frequency of television viewing and association with overweight or obesity among women of the reproductive age group in Myanmar: results from anationwide cross-sectional survey," BMJ Open, vol. 9, no. 3, Article ID e024680, 2019.

[56] S. Ghavamzadeh, H. R. Khalkhali, and M. Alizadeh, "TV viewing, independent of physical activity and obesogenic foods, increases overweightand obesity in adolescents," Journal of Health, Population and Nutrition, vol. 31, no. 3, pp. 334-342, 2013.

[57] V. Burke, L. J. Beilin, K. Durkin, W. G. K. Stritzke, S. Houghton, and C. A. Cameron, "Television, computer use, physical activity, diet and fatness in Australian adolescents," International Journal of Pediatric Obesity, vol. 1, no. 4, pp. 248-255, 2006.

[58] C.-Y. Chen, M. A. Pereira, K. H Kim et al., "Fifteen-Year prospective analysis of television viewing and adiposity in african American and caucasian men and women: the CARDIA study," SAGE Open, vol. 5, no. 3, Article ID 2158244015600480, 2015.

[59] S. Piryani, K. P. Baral, B. Pradhan, A. K. Poudyal, and R. M. Piryani, "Overweight and its associated risk factors among urban school adolescents in Nepal: across-sectional study," BMJ Open, vol. 6, no. 5, Article ID e010335, 2016.

[60] F. Xu, J. Li, R. S. Ware, and N. Owen, "Associations of television viewing time with excess body weight among urban and rural high-school students in regional mainland China," Public Health Nutrition, vol. 11, no. 9, pp. 891-896, 2008.

[61] G. R. Das, S. S. Haider, M. R Hashan et al., "Association between the frequency of television watching and overweight or obesity among women of reproductive age in Nepal: analysis of data from the Nepal Demographic and Health Survey 2016," PLoS One, vol. 15, no. 2, Article ID e0228862, 2020. 